\title{
Posttranslational regulation of copper transporters
}

\author{
Peter V. E. van den Berghe $\cdot$ Leo W. J. Klomp
}

Received: 4 August 2009/Accepted: 10 September 2009/Published online: 8 October 2009

(C) The Author(s) 2009. This article is published with open access at Springerlink.com

\begin{abstract}
Copper is an essential but potentially harmful trace element involved in many enzymatic processes that require redox chemistry. Cellular copper homeostasis in mammals is predominantly maintained by posttranslational regulation of copper import and export through the copper import proteins hCTR1 and hCTR2 and the copper exporters ATP7A and ATP7B. Regulation of copper uptake and export is achieved by modulation of transporter expression, copper-dependent and copper-independent trafficking of the different transporters, posttranslational modifications, and interacting proteins. In this review we systematically discuss the contribution of these different mechanisms to the regulation of copper transport.
\end{abstract}

Keywords Copper · Homeostasis · CTR1 - CTR2 · ATP7A $\cdot$ ATP7B

\section{Introduction}

Copper homeostasis is a strictly regulated process that balances the cellular need with the potential toxic nature of

This article will be printed in the upcoming Journal of Biological Inorganic Chemistry special issue Cell Biology of Copper.

P. V. E. van den Berghe · L. W. J. Klomp ( $)$

Department of Metabolic and Endocrine Diseases,

University Medical Center Utrecht, Lundlaan 6 (KC-02.069.1),

3584 EA Utrecht, The Netherlands

e-mail: L.Klomp@umcutrecht.nl

P. V. E. van den Berghe - L. W. J. Klomp

The Netherlands Metabolomics Center,

Utrecht, The Netherlands copper. Copper is a transition metal that can switch from the oxidized cupric $\left(\mathrm{Cu}^{2+}\right)$ to the reduced cuprous $\left(\mathrm{Cu}^{+}\right)$form by accepting or donating an electron. Owing to this redox activity, copper is an essential cofactor in many enzymatic pathways, including respiratory oxidation, neurotransmitter synthesis, iron metabolism, and pigmentation. This same redox activity can catalyze the Fenton reaction, yielding harmful reactive oxygen species. The necessity of copper homeostasis is clearly illustrated by two genetic disorders in humans in which the cellular copper-export machinery is severely impaired. The genes encoding the homologous copper-transporting $\mathrm{P}_{1 \mathrm{~B}}$-type ATPases ATP7A and ATP7B are mutated in the fatal $\mathrm{X}$-linked neurodevelopmental disorder Menkes disease (OMIM 309400) and the hepatolenticular copper-overload disorder Wilson disease (OMIM 277900), respectively. Mutation of ATP7A or ATP7B results in cellular copper accumulation, but Menkes disease and Wilson disease have very different clinical presentations owing to tissue-specific expression of these genes.

To maintain cellular copper homeostasis within narrow boundaries, cells have evolved intricate and essentially conserved systems of copper import, intracellular distribution, and copper export. Copper import in mammals is primarily mediated by the copper transporter (CTR) family of proteins that comprises the homologous CTR1 and CTR2. CTR1 is absolutely required for dietary copper absorption and is essential for cellular copper uptake [1-7]. Cellular copper export is equally important and is dependent on ATP7A and ATP7B [8-12]. In contrast to other organisms, hardly any transcriptional regulation of genes primarily involved in copper homeostasis exists in mammalian cells [13], and it is commonly accepted that regulation of copper homeostasis occurs predominantly by posttranslational mechanisms. We systematically discuss here the posttranslational regulation of copper homeostasis 
in mammalian cells. We focus on the regulation of copper import and export with respect to transporter protein structure, copper-dependent and copper-independent trafficking, and the role of posttranslational modifications and interacting proteins.

Structure-function relationship of copper-transporting P-type ATPases

Cellular copper export is dependent on the expression of ATP7A or ATP7B [9, 10, 14-18]. ATP7A and ATP7B have dual functions depending on the cellular copper status. As trans Golgi network (TGN)-resident proteins, they mediate copper transport into the biosynthetic pathway for subsequent incorporation in cuproenzymes. After relocalization to the plasma membrane or to vesicles at the cell periphery under conditions of copper overload, these proteins are essential for cellular copper export [9, 10, 14-18].

ATP7A and ATP7B share approximately 54\% homology. The overall topology of ATP7A and ATP7B is comparable. ATP7A and ATP7B have eight transmembrane helices and their amino termini and carboxy termini

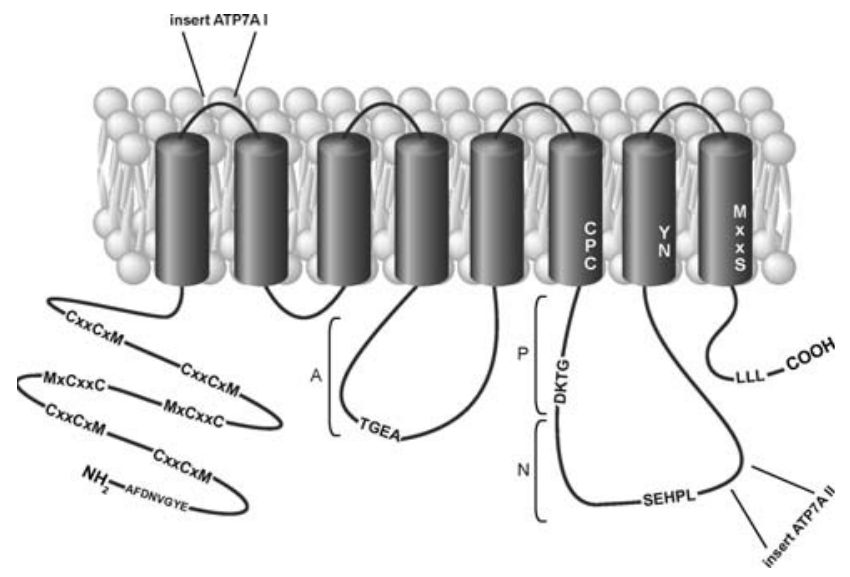

Fig. 1 Membrane topology and structural elements of copper-transporting P-type ATPases. ATP7A and ATP7B are transmembrane proteins with eight transmembrane helices. Several characteristic domains for P-type ATPases are involved in the catalytic cycle that mediates ion transport at the cost of ATP hydrolysis: the nucleotide binding domain $(N)$ with the conserved SEHPL motif; the phosphorylation domain $(P)$ with the invariant aspartic acid in the DKTG motif; and the actuator domain $(A)$ with the TGEA motif. Typical for the copper-transporting P-type ATPases are the Cys-Pro-Cys $(C P C)$, the Asp-Tyr $(Y N)$, and the Met-Xaa-Xaa-Ser $(M x x S)$ metal binding sites in the membrane domain that bind copper as part of the copperexport cycle in the sixth, seventh, and eighth transmembrane helices, respectively. The amino-terminal peptide contains six highly conserved copper-binding sites containing the MXCXXC motifs that bind copper and accept copper from the copper chaperone ATOX1, which contains a similar MXCXXC motif. The amino-terminal part of ATP7B contains the $\mathrm{F}_{37} \mathrm{AFDNVGYE}_{45}$ sequence that is involved in trafficking of ATP7B to the apical membrane, whereas a dileucine/ trileucine $(L L L)$ motif in the carboxy terminus in ATP7A and ATP7B is involved in retrograde transport to the trans Golgi network protrude into the cytosol (Fig. 1). The copper-transporting P-type ATPases contain several specific motifs that are essential for copper transport. Six metal binding domains (MBDs) are present in the amino-terminal domain of ATP7B and ATP7A, each comprising the typical Met-XaaCys-Xaa ${ }_{2}$-Cys (MXCXXC) copper-binding sites (Fig. 1). Structural analysis by NMR spectroscopy and X-ray spectroscopy revealed that these MBDs adopt a conserved $\beta \alpha \beta \beta \alpha \beta$ ferredoxin fold [19-24]. These copper-binding sites are surface-exposed and thus accessible for copper binding. To enable copper translocation across the membrane, P-type ATPases have a metal binding site (M-domain) in the transmembrane helices [25]. Copper coordination in the M-domain is essential for ATPasedependent copper transport, and therefore three transmembrane helices contain invariant residues that coordinate copper in the M-domain (Fig. 1); the Cys-Pro-Cys (CPC) motif in helix 6 [24], the Asp-Tyr (YN) motif in helix 7, and the Met-Xaa-Xaa-Ser (MxxS) motif in helix 8 coordinate copper in the M-domain [26-28]. Copper export by ATP7A and ATP7B is essentially dependent on the cyclic ATP hydrolysis activity [25]. ATP7A and ATP7B have several conserved motifs that are essential for their ATPase activity. These include the nucleotide-binding domain ( $\mathrm{N}$-domain), the phosphorylation domain (P-domain), and the actuator domain (A-domain) (Fig. 1).

Structure-function relationship of the copper-uptake proteins CTR1 and CTR2

CTR proteins are highly conserved members of the solute carrier superfamily expressed in eukaryotic cells. The human genome encodes two CTRs (hCTR1, SLC31A1; and hCTR2, SLC31A2). hCTR1 was identified as a highaffinity CTR by functional complementation of a yeast strain deficient in high-affinity copper uptake [29-32]. The characterization of CTR1 as a high-affinity CTR marked the start of extensive studies on the structure, function, and cellular localization of the CTR protein family $[2,6,7$, 33-42]. Overexpression of hCTR1 in several cell lines results in a substantial, specific, and saturable induction of cellular copper import with a $K_{\mathrm{m}}$ of approximately $1-5 \mu \mathrm{M}$ [7, 35, 39]. Ctr1 knockout mice died during midgestation, indicating an essential role for Ctr1 in embryonic development $[2,4]$. Interestingly, $\mathrm{Ctr}^{+/-}$mice that survived the embryonic stages displayed copper deficiencies in brain tissue, indicating that $\mathrm{Ctr} 1$ is indispensable for copper transport in mammals [2]. Mouse embryonic fibroblasts isolated from Ctr1 knockout mice have a substantial defect in copper uptake and copper incorporation into cuproenzymes [3]. Finally, analysis of conditional knockout mice that lack Ctr1 expression specifically in hepatocytes or in intestinal epithelial cells revealed a relatively minor 


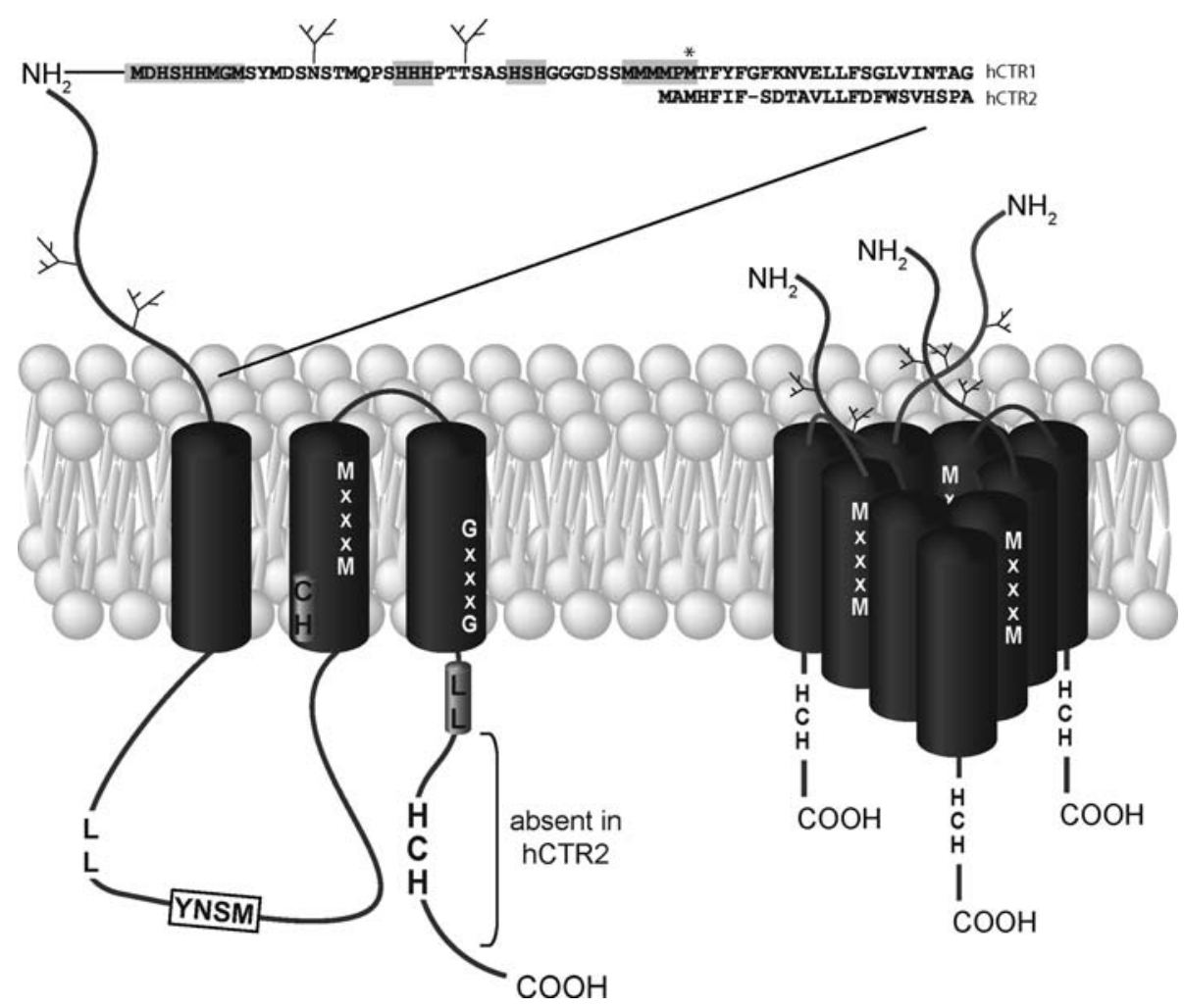

Fig. 2 Membrane topology and structural elements of the copperimport proteins hCTR 1 and hCTR2. hCTR 1 and hCTR2 are integral membrane proteins that contain three transmembrane helices with their amino termini exposed in the extracytoplasmic lumen, whereas the carboxy termini protrude into the cytosol (left). The amino terminus of hCTR1 is substituted with $\mathrm{N}$-linked glycans and O-linked glycans, whereas glycosylation is absent in hCTR2. The amino terminus of hCTR1 contains stretches of methionine and histidine residues (Mets motifs; gray boxes), which are absent in hCTR2. However, the penultimate methionine in hCTR1 that is required for copper uptake is also present in hCTR2 (asterisk). In contrast to hCTR1, hCTR2 has a significantly shorter carboxy-terminal tail that

contribution of Ctr1 to liver copper uptake [43], but an essential role for Ctr1 in intestinal copper uptake [5]. hCTR2 was only recently characterized as a functional CTR that mediates copper uptake with relatively low affinity compared with hCTR1 [6, 7].

Studies in yeast and mammalian cells revealed that CTR proteins are integral membrane proteins, which contain three transmembrane helices. Extensive experimental evidence supports the topological model described in Fig. 2 $[37,39,40,44]$. The carboxy terminus protrudes in the cytosol, whereas the amino terminus is located at the extracytoplasmic side of the membrane. The amino terminus of CTR1 contains a number of conserved methionine and histidine residues, arranged in so-called Mets motifs. These motifs likely contribute the sulfhydryl ligands that coordinate copper for subsequent transport. Whereas only the penultimate methionine in these motifs is absolutely required for copper transport, their presence highly lacks the His-Cys-His $(\mathrm{HCH})$ motif, but the Cys-His $(\mathrm{CH})$ motif in the second transmembrane helix might fulfill a similar role in hCTR2. Furthermore, hCTR2 contains a dileucine motif in its carboxy terminus, which might be involved in internalization of hCTR2. Both hCTR 1 and hCTR 2 contain a dileucine $(L L)$ motif in the cytoplasmic loop. hCTR1 contains a putative YNSM internalization motif (boxed). Within the transmembrane helices, hCTR1 and hCTR2 contain the conserved Met-Xaa ${ }_{3}$-Met $(M x x x M)$ motif, which is essential for copper transport, and the Gly-Xaa ${ }_{3}$-Gly $(G x x x G)$ motif, which is involved in interhelical interactions. Evidence from literature indicates that hCTR1 (and hCTR2) functions as a trimer to create an aqueous pore that is large enough to enable copper transport (right)

increases copper transport affinity [41]. In contrast, CTR2 lacks these Mets-motifs with the exception of the penultimate methionine, providing an explanation for the reduced affinity compared with CTR1. The amino terminus of hCTR1 is substituted with $\mathrm{N}$ - and O-linked oligosaccharides $[37,45]$. The function of the $\mathrm{N}$-linked glycosylation is not completely clear, whereas the O-linked glycans are possibly involved in the stability of the protein [45].

Biochemical analysis and electron microscopic crystallography revealed that hCTR1 subunits assemble as homooligomeric complexes comprising three hCTR1 subunits [7, 33, 34, 37, 39]. Homo-oligomerization may involve mutual interactions of the amino termini of hCTR 1 , as was suggested by yeast-two-hybrid experiments [37]. A cysteine residue in the carboxy terminus [36] and a Gly-Xaa ${ }_{3}-$ Gly sequence in the second transmembrane helix [33, 34] have also been implicated in hCTR1 oligomerization. Together, these data support the notion that multiple 
domains within CTR1 proteins contribute to the formation of oligomeric transporters. Electron microscopy analysis of protein crystals comprising recombinant hCTR1 reconstituted in native phospholipid bilayers permitted determination of the structure of the hCTR1 oligomer at approximately $6-\AA$ resolution. These studies revealed that hCTR1 forms compact trimeric complexes containing nine transmembrane helices [33, 34]. Experiments using hCTR2 indicated that oligomerization is a general characteristic of human CTR proteins [7]. These data suggest that oligomerization of hCTR1 is required for functional highaffinity copper transport activity by permitting the formation of copper-permeable channels necessary for copper uptake. Formation of such channels would permit copper transport by coordination of copper by a series of six methionine residues buried within the transmembrane helices of the CTR trimer. Finally, the cytoplasmic carboxy-terminal domain of hCTR1 contains a conserved HisCys-His motif, which may generate the thermodynamic energy that drives copper import and which may prevent unregulated entry of "free" copper into the cytosol.

\section{Posttranslational regulation of copper transport}

Regulation of subcellular localization

and copper-dependent protein trafficking

Under basal (low-copper) conditions, ATP7A and ATP7B display a characteristic perinuclear localization $[9,11,46]$, which has been identified as the TGN by immunogold electron microscopy [47]. Endogenous as well as overexpressed ATP7A and ATP7B were detected in the TGN in a wide variety of polarized and nonpolarized cell types under basal copper conditions, both in vitro and in vivo $[9,11,12$, 14, 47-62]. In ATP7A, a putative TGN-targeting signal was identified within transmembrane helix 3 [54]. A certain degree of homology within this region is present between ATP7A and ATP7B, but it is currently unknown whether transmembrane helix 3 in ATP7B contains a similar TGNtargeting signal. Recent studies localized ATP7B to tight junctions in hepatocytes, where it might be involved in paracellular copper transport [63]. Taken together, the general consensus is that ATP7A and ATP7B are localized in the TGN under basal copper conditions. Incorporation of copper into nascent cuproenzymes such as ceruloplasmin in the TGN is dependent on expression of ATP7A and ATP7B, which is consistent with the localization of ATP7A and ATP7B in the TGN [64].

In most of these studies, copper-dependent localization of ATP7A and ATP7B to post-Golgi vesicles or to the plasma membrane was observed. This copper-dependent relocalization of copper-transporting P-type ATPases is metal-specific, fast, does not require de novo protein synthesis, and is reversible. Although ATP7A and ATP7B both traffic in response to copper, their destination is clearly different. Under high-copper conditions, ATP7B displays overlap with the apical membrane in several polarized hepatic cell lines [12, 51, 53], whereas others observed that ATP7B does not traffic preferentially to the plasma membrane but traffics to post-Golgi vesicles instead $[9,46,52,65,66]$. Both in vitro and in vivo experiments have illustrated copper-dependent trafficking of ATP7B in hepatocytes [12, 51, 53, 67]. It appears that copper-induced trafficking of ATP7B is a cell-type-specific phenomenon. Barnes et al. [68] demonstrated that copperinduced trafficking of endogenously expressed ATP7B in kidney-derived HEK293T cells, MDCK cells, Cos-7 cells, or primary kidney cells was perturbed, whereas copperdependent trafficking of ATP7A did take place in these same cell types. Reversible copper-dependent trafficking of ATP7A to the plasma membrane or post-Golgi vesicles in nonpolarized cells $[11,54-58]$ and specifically towards the basolateral membrane in polarized cells [59-62, 69, 70] was observed.

Specific targeting of ATP7B towards the apical membrane is dependent on an ATP7B-specific sequence, $\mathrm{F}_{37} \mathrm{AFDNVGYE}_{45}$, and disruption of this motif results in basolateral targeting [71] (Fig. 1). This sequence motif is absent in ATP7A, and overexpression of ATP7A in hepatocytes results in basolateral localization [70]. Deletion of an ATP7A-specific PDZ-domain in the carboxy terminus of ATP7A results in apical localization of ATP7A in hepatocytes [70]. Apparently, these motifs are required for trafficking to distinct membranes.

Retrograde transport of ATP7A and ATP7B back to the TGN is induced by restoring copper concentrations to basal levels [65]. A dileucine sequence in the carboxy-terminal tail of ATP7A is required for retrograde transport to the TGN [72-74]. This dileucine motif might induce classic clathrin-dependent endocytosis of ATP7A [75], but contradicting observations showed that endocytosis of ATP7A is also clathrin-independent [75, 76]. Apparently, other sequences contribute to the retrograde transport of ATP7A. ATP7B has a comparable trileucine motif in its carboxyterminal tail (Fig. 1). Mutation of the trileucine in ATP7B does not result in retention at the plasma membrane, but ATP7B is constitutively localized in post-Golgi vesicles instead [76]. Thus, the dileucine/trileucine clearly functions in retrograde transport of ATP7A and ATP7B.

Copper transport activity strongly correlates with copper-induced trafficking of both ATP7A and ATP7B. Mutation of the CPC copper-binding site in the transmembrane region prevents copper binding and copper-induced relocalization [70, 77, 78], but results in a constitutive localization in post-Golgi vesicles, concomitant with 
increased phosphorylation of the invariant D1027 in the P-domain in ATP7B [57]. Furthermore, mutation D1027 in ATP7B abolishes copper-induced trafficking from the TGN to post-Golgi vesicles [52]. In contrast, mutation of the TGEA motif results in localization of ATP7A in post-Golgi vesicles and this localization is no longer affected by changes in copper concentrations [78]. More importantly, combining the TGEA mutation with deletion of the six amino-terminal MBDs and the CPC motif in ATP7B cannot reverse the peripheral localization [52]. Apparently, copperdependent localization of copper-transporting P-type ATPases is dependent on the progression through the different conformational stages associated with the catalytic cycle.

hCTR1 is predominantly localized in intracellular organelles, but a smaller or larger proportion of hCTR1 is exposed on the plasma membrane depending on the cell type (Fig. 3) [38, 39, 79]. The subcellular localization of hCTR1 is regulated by extracellular copper concentrations. In steady-state conditions, hCTR1 constitutively cycles between intracellular organelles and the plasma membrane [38]. The cell surface pool of hCTR1 is rapidly internalized and subsequently degraded in response to high copper concentrations $\left(200 \mu \mathrm{M} \mathrm{CuCl}_{2}\right)$ [40]. This is dependent on the Mets motifs in the amino terminus of hCTR1 [44]. This forms a putative regulatory mechanism to prevent toxic copper accumulation in the cell. In contrast, hCTR2 is exclusively localized in endosomes and lysosomes, and its localization is not affected by changes in the extracellular copper concentration [7].

Comparison of hCTR1 and hCTR2 revealed highly conserved dileucine motifs in their cytoplasmic loops, whereas hCTR2 has an additional dileucine motif in its carboxy terminus (Fig. 1). Furthermore, hCTR1 contains a putative Tyr-Xaa 2 -(hydrophobic amino acid) internalization motif in its cytoplasmic loop: Tyr-Asn-Ser-Met (Fig. 2) [80]. Conformational changes induced by copper binding might expose these motifs to the endocytosis machinery, resulting in subsequent internalization. The two dileucine motifs in hCTR2 might strengthen the internalization potential of hCTR2, which could imply that hCTR2 only transiently appears at the plasma membrane followed by immediate internalization into the endocytic pathway. The contribution of these motifs to the subcellular localization requires further investigation.

Copper-independent regulation of hCTR1, ATP7A and ATP7B trafficking, and protein expression

Stimuli other than copper affect the localization of copper transport proteins in different tissues. Activation of the NMDA receptor by glutamate in hippocampal neurons results in reversible and copper-independent trafficking of
ATP7A from the TGN to neuronal processes [81]. This results in glutamate-dependent copper excretion, which prevents neuronal cell death owing to NMDA-receptor activation [82]. Another tissue-specific copper-independent localization pathway is present in melanocytes. These cells require copper transport into melanosomes, where the cuproenzyme tyrosinase mediates maturation of promelanin into melanin (pigment). After synthesis, tyrosinase incorporates copper in the TGN, but the enzyme loses bound copper during progression to the endocytic compartments. Interestingly, ATP7A is partially localized to melanosomes [83]. Hence, copper-independent localization of ATP7A to melanosomes ascertains organelle-specific tyrosinase activity. Copper transport in macrophages is regulated in an oxygen-dependent manner. Hypoxia induces ATP7A protein expression and trafficking of ATP7A from the TGN to post-Golgi vesicles in a copper-dependent manner [84]. Furthermore, hCTR1 protein expression and copper uptake are induced by hypoxia. During hypoxia, copper delivery to $\mathrm{Cu} / \mathrm{Zn}$ dismutase (SOD1) and to COX1, a subunit of cytochrome $c$ oxidase, is inhibited, whereas more copper is incorporated into ceruloplasmin in the secretory pathway by ATP7A [84]. Apparently, hypoxia results in an increased copper uptake and a redistribution of copper to different compartments in the cell to adapt to cellular need. The latter strongly suggests that copper uptake, distribution, and export are coordinately regulated (Fig. 3).

Mother-to-fetus transport of copper in placental trophoblasts is dependent on ATP7A as well as ATP7B [62, 69, 85]. Interestingly, several hormones regulate expression and localization of these proteins. Estrogen and insulin result in upregulation of ATP7A messenger RNA and protein expression [69]. These hormones induce copper-independent trafficking of ATP7A from the TGN to the basolateral membrane (fetal side of the cell). At the same time, stimulation with these hormones results in decreased ATP7B protein expression, and retention of ATP7B in the TGN to prevent copper excretion at the apical (maternal) side of the membrane. A minor increase in hCTR1 protein expression was observed in JEG-3 placental cells after stimulation with estrogen or progesterone. hCTR1 is localized at the lateral membranes of polarized JEG-3 cells, but no clear changes in localization are observed in response to hormone treatment [61]. In contrast, lactogenic hormones trigger ATP7B relocalization to the apical membrane (milk side) in mammary tissue, which results in copper export to the milk [60]. Treatment with prolactin results in increased copper excretion into the milk by basolateral localization of CTR1 and ATP7A [59]. These observations suggest that localization of copper transport proteins is regulated in a coordinated manner in mammary gland tissue. 


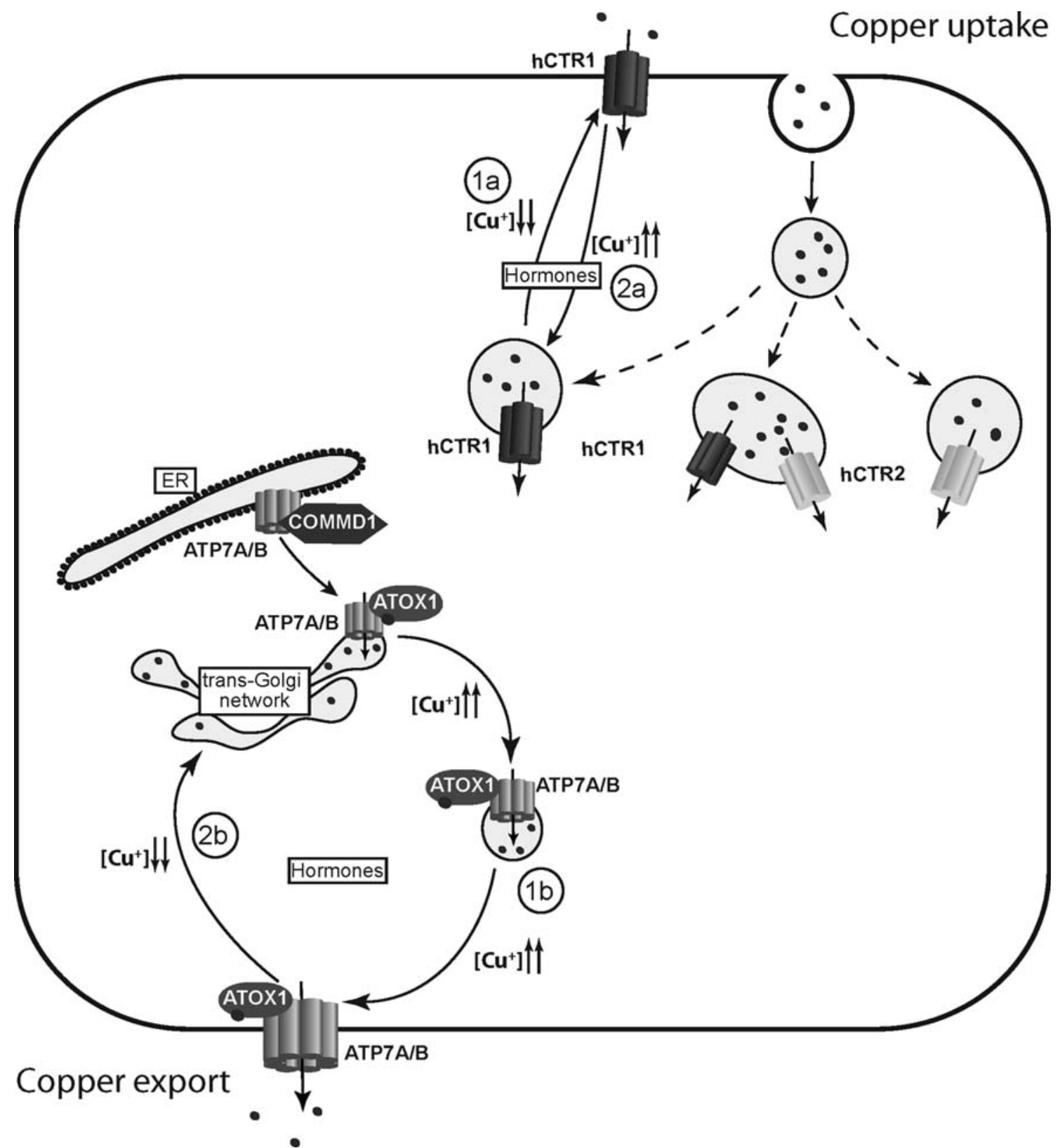

Fig. 3 Regulation of cellular copper transport. Cellular copper uptake is dependent on hCTR1. Most of the hCTR1 is located in intracellular organelles in steady-state conditions, with a fraction of the hCTR1 present on the plasma membrane. Increased extracellular copper concentrations result in internalization of hCTR1 (la), and subsequent degradation. Reduction of the extracellular copper concentration results in repopulation of hCTR1 at the surface $(2 a)$.

Copper transport is tightly correlated to resistance to a group of cytotoxic platinum drugs that are used in cancer treatment, such as cisplatin. Cisplatin enters the cell in an hCTR1-dependent manner [86, 87], and expression of hCTR1 is downregulated by cisplatin. Cisplatin also regulates its own export by modulating expression of ATP7A and ATP7B. Increased expression of ATP7A and ATP7B correlates with decreased sensitivity to cisplatin $[88,89]$.
Copper export is regulated in a similar fashion as an increase in extracellular copper is sensed intracellularly and is converted to trafficking of ATP7A/ATP7B to the cell periphery or cell surface (1b). Similarly, removal of the excessive copper results in relocalization of ATP7A/ATP7B to the trans Golgi network (2b). Similar trafficking events can also be induced by hormones or the oxygen concentration depending on the cell type

Regulation of copper transport by protein-protein interactions

Protein-protein interactions as a potential way to regulate activity of the different copper transport proteins have attracted much recent attention. Protein-protein interactions are known to manipulate protein localization, degradation, and posttranslational modifications such as phosphorylation 
and ubiquitination and many other processes. In addition, protein-protein interactions themselves are regulated by posttranslational modifications. Copper binding to ATP7A and ATP7B forms a key event in the catalytic cycle. An essential step in ATP7A- and ATP7B-dependent copper transport is copper delivery by the copper chaperone ATOX1 [90-93]. The importance of ATOX1 in mammalian biology is clearly illustrated by the Atoxl knockout mice that displayed a copper deficiency phenotype similar to Menkes disease [90]. ATOX1 contains an MBD with significant homology and similar fold compared with the MBDs of ATP7A and ATP7B [94], enabling copperdependent dimerization of these motifs [95] and copper transfer between the copper-binding sites of ATOX1 and the copper-transporting P-type ATPases. The interaction between ATOX1 and ATP7A or ATP7B is essential for copper translocation and for copper-dependent trafficking of ATP7A and ATP7B [10, 11, 48, 55-58, 70, 77, 78, 91, 92, 96-100]. ATOX1 interacts with all MBDs in vitro in a copper-dependent manner [101], but the different MBDs are not equally involved in the regulation of copper-transporting P-type ATPases.

ATOX1-dependent copper delivery to the amino-terminal MBDs in ATP7A and ATP7B was long thought to be the mechanism of copper delivery into the copper-binding sites in the M-domain. Arguello and Gonzalez-Guerrero [102] recently postulated a novel theory in which the amino-terminal MBDs regulate ATPase activity. Copper delivery to the amino-terminal MBDs by ATOX1 disrupts the interaction of the amino terminus and the N-domain. This enables ATP binding to the N-domain and allows ATOX1 to deliver copper to the copper-binding sites in the M-domain, thereby stimulating copper translocation by these ATPases [103]. ATOX1 also interacts with the immunophillin FKBP52 [104], a protein involved in protein trafficking, but the exact mechanisms by which FKBP52 attenuates its role in the copper excretion pathway need to be further characterized.

Recently, two novel ATP7B-interacting proteins were identified by yeast-two-hybrid analyses [105-107]. First, glutaredoxin displays a copper-dependent interaction with ATP7A and ATP7B [106], and this interaction is dependent on the availability of the MBDs in the amino terminus. Glutaredoxins are involved in keeping cysteine thiols in a reduced state. This may be a mechanism to keep the cysteines in the MXCXXC motifs available for copper binding by preventing the formation of intramolecular disulfide bonds that are not accessible for copper coordination [106]. Second, the amino terminus of ATP7B interacts with the dynactin subunit p62 in a copper-dependent manner [105]. The dynactin complex is involved in mobilization of organelles along microtubules [108], suggesting that this interaction may be involved in copper-dependent relocalization of ATP7B. Of note, copper-independent interaction with the carboxy terminus of ATP7A and the PDZ-domain containing protein ATPase-interacting PDZ protein was recently described [107]. These proteins are involved in membrane trafficking, but their function in ATP7A regulation is currently unclear.

One of the other ATP7B-interacting proteins that recently attracted attention is COMMD1. COMMD1 was characterized as the protein that was deleted in Bedlington terriers affected by hereditary copper toxicosis [109-111]. The exact function of COMMD1 in copper metabolism is currently unknown. Although it has been reported that COMMD1 binds $\mathrm{Cu}^{2+}$ [112], a direct and copper-independent interaction between the amino terminus of ATP7B and COMMD1 has been characterized [113, 114]. Transient knockdown of COMMD1 by RNA interference results in increased cellular copper levels in HEK293T cells [115-117]. Together, these data suggest that ATP7B and COMMD1 cooperate in cellular copper export, which might be the underlying defect in Bedlington terriers affected by copper toxicosis. Interestingly, the interaction between COMMD1 and ATP7B is markedly increased when Wilson-disease-associated mutations of ATP7B are present $[114,118]$. These mutations are associated with misfolding, mislocalization of ATP7B to the endoplasmic reticulum, and decreased protein expression due to increased proteasomal degradation. COMMD1 has been implicated in regulation of protein stability of components of the NF- $\kappa \mathrm{B}$ and HIF1 signaling pathways [119-122]. These observations suggest that COMMD1 may affect copper homeostasis by regulating the stability of newly synthesized ATP7B.

With the exception of homo-oligomerization of CTR1, no interacting proteins have been identified for the CTR proteins, but it is speculated that CTR-mediated copper transport is coupled to protein-interaction-dependent transfer of copper to cytoplasmic proteins such as the known copper chaperones. In addition, copper-responsive internalization of CTR1 from the plasma membrane likely involves interacting proteins.

Regulation of copper transport by posttranslational modifications

Signal transduction pathways that confer transient posttranslational protein modifications, such as phosphorylation, acetylation, and ubiquitination, dictate the expression, localization, stability, and function of many proteins. Degradation of newly synthesized ATP7B can be partly inhibited by inhibitors of proteasomal degradation, suggesting that ATP7B expression is regulated by polyubiquitination [114]. To date, no ubquitination sites have directly been characterized in ATP7A or ATP7B. Internalization of Ctr1p 
in Saccharomyces ceriviseae requires ubiquitination of two carboxy-terminal lysine residues (Lys340 and Lys345) of Ctr1p [123]. However, these lysine residues are not conserved, and the role of ubiquitination on trafficking of mammalian CTR1 remains elusive. In analogy with other membrane proteins, it is likely that trafficking and degradation are regulated by specific monoubiquitination or polyubiquitination [124].

Phosphorylation of ATP7B, in a manner distinct from the transient phosphorylation of the invariant D1027 during the catalytic cycle, has been described and correlated with localization of ATP7B to the periphery of the cell [125]. This hyperphosphorylation of ATP7B appears dependent on copper and on the presence of an intact amino terminus $[125,126]$. In contrast, copper depletion results in dephosphorylation of ATP7B and concomitant retrograde trafficking of ATP7B to the TGN [125]. The kinase responsible for this phosphorylation event is currently unknown, but it is tempting to speculate that coupling of protein phosphorylation to copper binding at the aminoterminal domains of copper-transporting P-type ATPases comprises the mechanism by which the amino terminus regulates protein function and localization in a copperdependent way. Alternatively, it is also possible that copper-initiated signal transduction pathways exist and result in phosphorylation of ATP7A or ATP7B. Furthermore, a basal phosphorylation site that is independent of copper was characterized, and involves serine residues in the carboxy-terminal Ser796-Tyr1384 region of ATP7B [125, 126]. The function of basal phosphorylation is currently unknown, but it may be involved in interactions with proteins either to retain ATP7B in the TGN or to modulate copper transport activity.

Recently, several novel serine phosphorylation sites have been identified in the amino terminus and carboxy terminus of ATP7A. Phosphorylation of Ser1342 and Ser1469 is essential for copper-dependent trafficking from the TGN to the plasma membrane [127]. However, copperdependent trafficking per se is not affected by mutations in these sites, suggesting that these serines possibly regulate direction of trafficking. These sites are strongly conserved in ATP7B, suggesting that regulation of trafficking by copper-dependent phosphorylation is conserved. These observations mark an important step forward in our understanding of regulation of copper ATPases by phosphorylation. Interestingly, some of these phosphorylation sites are in close proximity to the PDZ-domain in ATP7A and the dileucine/trileucine motif involved in internalization. It is tempting to speculate that phosphorylation at these sites modulates specific protein-protein interactions at these different motifs, and thereby affects cellular localization. In conclusion, identification of the exact phosphorylation sites, the consequences of phosphorylation and the kinases responsible will greatly enhance our understanding of regulation of ATP7B function. In addition, there is great demand for identification of other potential posttranslational modifications of copper-transporting P-type ATPases.

\section{Conclusions}

The regulation of ATP7A- and ATP7B-dependent copper translocation and the regulation of the spatial distribution of copper transport proteins in cells have been intensively studied during the past few decades. The copper-dependent trafficking of ATP7A and ATP7B is correlated to their catalytic activity, but hardly any information is available on the mechanisms that facilitate this relocalization. The regulated trafficking to specific organelles and membranes in the cell requires posttranslational modifications and protein-protein interactions to direct these proteins to their specific destinations. The catalytic activity of ATP7A and ATP7B is regulated by intermolecular and intramolecular interactions comprising the amino termini and N-domains of ATP7A, ATP7B, and ATOX1. However, the contribution of copper-dependent phosphorylation to catalytic activity remains elusive. With the current development of high-throughput proteomics and high-throughput imaging systems much is to be expected in the further characterization of protein modification and the effects on copper transport, transporter localization, and regulation. Especially for the copperimport proteins hCTR1 and hCTR2, understanding of their regulation, modifications, and interacting proteins is required.

Acknowledgments NWO Program Grant 912.04.106 and NWO ALW Grant 817.02.022 to L.W.J.K are acknowledged.

Open Access This article is distributed under the terms of the Creative Commons Attribution Noncommercial License which permits any noncommercial use, distribution, and reproduction in any medium, provided the original author(s) and source are credited.

\section{References}

1. Kuo YM, Gybina AA, Pyatskowit JW, Gitschier J, Prohaska JR (2006) J Nutr 136:21-26

2. Kuo YM, Zhou B, Cosco D, Gitschier J (2001) Proc Natl Acad Sci USA 98:6836-6841

3. Lee J, Petris MJ, Thiele DJ (2002) J Biol Chem 277:4025340259

4. Lee J, Prohaska JR, Thiele DJ (2001) Proc Natl Acad Sci USA 98:6842-6847

5. Nose Y, Kim BE, Thiele DJ (2006) Cell Metab 4:235-244

6. Bertinato J, Swist E, Plouffe LJ, Brooks SP, L'Abbe MR (2008) Biochem J 409:731-740 
7. van den Berghe PV, Folmer DE, Malingré HE, van Beurden E, Klomp AE, van de Sluis B, Merkx M, Berger R, Klomp LW (2007) Biochem J 407:49-59

8. Holzer AK, Manorek GH, Howell SB (2006) Mol Pharmacol 70:1390-1394

9. Hung IH, Suzuki M, Yamaguchi Y, Yuan DS, Klausner RD, Gitlin JD (1997) J Biol Chem 272:21461-21466

10. Payne AS, Gitlin JD (1998) J Biol Chem 273:3765-3770

11. Petris MJ, Mercer JF, Culvenor JG, Lockhart P, Gleeson PA, Camakaris J (1996) EMBO J 15:6084-6095

12. Roelofsen H, Wolters H, Van Luyn MJ, Miura N, Kuipers F, Vonk RJ (2000) Gastroenterology 119:782-793

13. Muller P, van Bakel H, van de Sluis B, Holstege F, Wijmenga C, Klomp LW (2007) J Biol Inorg Chem 12:495-507

14. La Fontaine SL, Firth SD, Camakaris J, Englezou A, Theophilos MB, Petris MJ, Howie M, Lockhart PJ, Greenough M, Brooks H, Reddel RR, Mercer JF (1998) J Biol Chem 273:31375-31380

15. Camakaris J, Petris MJ, Bailey L, Shen P, Lockhart P, Glover TW, Barcroft C, Patton J, Mercer JF (1995) Hum Mol Genet 4:2117-2123

16. Katano K, Safaei R, Samimi G, Holzer A, Rochdi M, Howell SB (2003) Mol Pharmacol 64:466-473

17. La Fontaine S, Firth SD, Lockhart PJ, Brooks H, Parton RG, Camakaris J, Mercer JF (1998) Hum Mol Genet 7:1293-1300

18. Voskoboinik I, Greenough M, La Fontaine S, Mercer JF, Camakaris J (2001) Biochem Biophys Res Commun 281:966970

19. Banci L, Bertini I, Ciofi-Baffoni S, Chasapis CT, Hadjiliadis N, Rosato A (2005) FEBS J 272:865-871

20. Banci L, Bertini I, Del Conte R, D’Onofrio M, Rosato A (2004) Biochemistry 43:3396-3403

21. DeSilva TM, Veglia G, Opella SJ (2005) Proteins 61:1038-1049

22. Jensen PY, Bonander N, Karlsson BG, Horn N, Tumer Z, Farver O (1998) J Inherit Metab Dis 21:195-198

23. Jones CE, Daly NL, Cobine PA, Craik DJ, Dameron CT (2003) J Struct Biol 143:209-218

24. Myari A, Hadjiliadis N, Fatemi N, Sarkar B (2004) J Inorg Biochem 98:1483-1494

25. Kuhlbrandt W (2004) Nat Rev Mol Cell Biol 5:282-295

26. Arguello JM, Eren E, Gonzalez-Guerrero M (2007) Biometals 20:233-248

27. Gonzalez-Guerrero M, Arguello JM (2008) Proc Natl Acad Sci USA 105:5992-5997

28. Mandal AK, Yang Y, Kertesz TM, Arguello JM (2004) J Biol Chem 279:54802-54807

29. Dancis A, Yuan DS, Haile D, Askwith C, Eide D, Moehle C, Kaplan J, Klausner RD (1994) Cell 76:393-402

30. Kampfenkel K, Kushnir S, Babiychuk E, Inze D, Van Montagu M (1995) J Biol Chem 270:28479-28486

31. Knight SA, Labbe S, Kwon LF, Kosman DJ, Thiele DJ (1996) Genes Dev 10:1917-1929

32. Zhou B, Gitschier J (1997) Proc Natl Acad Sci USA 94:74817486

33. Aller SG, Eng ET, De Feo CJ, Unger VM (2004) J Biol Chem 279:53435-53441

34. Aller SG, Unger VM (2006) Proc Natl Acad Sci USA 103:36273632

35. Eisses JF, Kaplan JH (2002) J Biol Chem 277:29162-29171

36. Eisses JF, Kaplan JH (2005) J Biol Chem 280:37159-37168

37. Klomp AE, Juijn JA, van der Gun LT, van den Berg IE, Berger R, Klomp LW (2003) Biochem J 370:881-889

38. Klomp AE, Tops BB, Van Denberg IE, Berger R, Klomp LW (2002) Biochem J 364:497-505

39. Lee J, Peña MM, Nose Y, Thiele DJ (2002) J Biol Chem 277:4380-4387
40. Petris MJ, Smith K, Lee J, Thiele DJ (2003) J Biol Chem 278:9639-9646

41. Puig S, Lee J, Lau M, Thiele DJ (2002) J Biol Chem 277:2602126030

42. Puig S, Thiele DJ (2002) Curr Opin Chem Biol 6:171-180

43. Kim H, Son HY, Bailey SM, Lee J (2009) Am J Physiol Gastrointest Liver Physiol 296(2):G356-G364

44. Guo Y, Smith K, Lee J, Thiele DJ, Petris MJ (2004) J Biol Chem 279:17428-17433

45. Maryon EB, Molloy SA, Kaplan JH (2007) J Biol Chem 282:20376-20387

46. Yamaguchi Y, Heiny ME, Suzuki M, Gitlin JD (1996) Proc Natl Acad Sci USA 93:14030-14035

47. Huster D, Hoppert M, Lutsenko S, Zinke J, Lehmann C, Mossner J, Berr F, Caca K (2003) Gastroenterology 124:335345

48. Forbes JR, Cox DW (2000) Hum Mol Genet 9(13):1927-1935

49. Yang XL, Miura N, Kawarada Y, Terada K, Petrukhin K, Gilliam T, Sugiyama T (1997) Biochem J 326(3):897-902

50. La Fontaine S, Theophilos MB, Firth SD, Gould R, Parton RG, Mercer JF (2001) Hum Mol Genet 10:361-370

51. Bartee MY, Lutsenko S (2007) Biometals 20:627-637

52. Cater MA, La Fontaine S, Shield K, Deal Y, Mercer JF (2006) Gastroenterology 130:493-506

53. Guo Y, Nyasae L, Braiterman LT, Hubbard AL (2005) Am J Physiol Gastrointest Liver Physiol 289:G904-G916

54. Francis MJ, Jones EE, Levy ER, Ponnambalam S, Chelly J, Monaco AP (1998) Hum Mol Genet 7:1245-1252

55. Goodyer ID, Jones EE, Monaco AP, Francis MJ (1999) Hum Mol Genet 8:1473-1478

56. Huster D, Lutsenko S (2003) J Biol Chem 278:32212-32218

57. Cater MA, La Fontaine S, Mercer JF (2007) Biochem J 401:143-153

58. Strausak D, La Fontaine S, Hill J, Firth SD, Lockhart PJ, Mercer JF (1999) J Biol Chem 274:11170-11177

59. Kelleher SL, Lönnerdal B (2006) Am J Physiol Regul Integr Comp Physiol 291:R1181-R1191

60. Michalczyk A, Bastow E, Greenough M, Camakaris J, Freestone D, Taylor P, Linder M, Mercer J, Ackland ML (2008) J Histochem Cytochem 56:389-399

61. Hardman B, Manuelpillai U, Wallace EM, Monty JF, Kramer DR, Kuo YM, Mercer JF, Ackland ML (2006) Placenta 27:968977

62. Hardman B, Michalczyk A, Greenough M, Camakaris J, Mercer J, Ackland L (2007) Cell Physiol Biochem 20:1073-1084

63. Hernandez S, Tsuchiya Y, García-Ruiz JP, Lalioti V, Nielsen S, Cassio D, Sandoval IV (2008) Gastroenterology 134:1215-1223

64. Fleming RE, Gitlin JD (1990) J Biol Chem 265:7701-7707

65. Schaefer M, Hopkins RG, Failla ML, Gitlin JD (1999) Am J Physiol 276:G639-G646

66. Suzuki M, Gitlin JD (1999) Pediatr Int 41:436-442

67. Schaefer M, Gitlin JD (1999) Am J Physiol 276:G311-G314

68. Barnes N, Bartee MY, Braiterman L, Gupta A, Ustiyan V, Zuzel V, Kaplan JH, Hubbard AL, Lutsenko S (2009) Traffic 10(6):767-779

69. Hardman B, Michalczyk A, Greenough M, Camakaris J, Mercer JF, Ackland ML (2007) Biochem J 402:241-250

70. Greenough M, Pase L, Voskoboinik I, Petris MJ, O'Brien AW, Camakaris J (2004) Am J Physiol Cell Physiol 287:C1463C1471

71. Braiterman L, Nyasae L, Guo Y, Bustos R, Lutsenko S, Hubbard A (2009) Am J Physiol Gastrointest Liver Physiol 296(2):G433-G444

72. Francis MJ, Jones EE, Levy ER, Martin RL, Ponnambalam S, Monaco AP (1999) J Cell Sci 112(11):1721-1732 
73. Petris MJ, Camakaris J, Greenough M, LaFontaine S, Mercer JF (1998) Hum Mol Genet 7:2063-2071

74. Petris MJ, Mercer JF (1999) Hum Mol Genet 8:2107-2115

75. Lane C, Petris MJ, Benmerah A, Greenough M, Camakaris J (2004) Biometals 17:87-98

76. Cobbold C, Coventry J, Ponnambalam S, Monaco AP (2003) Hum Mol Genet 12:1523-1533

77. Mercer JF, Barnes N, Stevenson J, Strausak D, Llanos RM (2003) Biometals 16:175-184

78. Petris MJ, Voskoboinik I, Cater M, Smith K, Kim BE, Llanos RM, Strausak D, Camakaris J, Mercer JF (2002) J Biol Chem 277:46736-46742

79. Zimnicka AM, Maryon EB, Kaplan JH (2007) J Biol Chem 282:26471-26480

80. Wilde A, Dempsey C, Banting G (1994) J Biol Chem 269:71317136

81. Schlief ML, Craig AM, Gitlin JD (2005) J Neurosci 25:239-246

82. Schlief ML, West T, Craig AM, Holtzman DM, Gitlin JD (2006) Proc Natl Acad Sci USA 103:14919-14924

83. Setty SR, Tenza D, Sviderskaya EV, Bennett DC, Raposo G, Marks MS (2008) Nature 454:1142-1146

84. White C, Kambe T, Fulcher YG, Sachdev SW, Bush AI, Fritsche K, Lee J, Quinn TP, Petris MJ (2009) J Cell Sci 122: 1315-1321

85. Richardson DR, Suryo Rahmanto Y (2007) Biochem J 402:e1e3

86. Holzer AK, Samimi G, Katano K, Naerdemann W, Lin X, Safaei R, Howell SB (2004) Mol Pharmacol 66:817-823

87. Ishida S, Lee J, Thiele DJ, Herskowitz I (2002) Proc Natl Acad Sci USA 99:14298-14302

88. Safaei R, Otani S, Larson BJ, Rasmussen ML, Howell SB (2008) Mol Pharmacol 73:461-468

89. Samimi G, Varki NM, Wilczynski S, Safaei R, Alberts DS, Howell SB (2003) Clin Cancer Res 9:5853-5859

90. Hamza I, Faisst A, Prohaska J, Chen J, Gruss P, Gitlin JD (2001) Proc Natl Acad Sci USA 98:6848-6852

91. Hamza I, Prohaska J, Gitlin JD (2003) Proc Natl Acad Sci USA 100:1215-1220

92. Hamza I, Schaefer M, Klomp LW, Gitlin JD (1999) Proc Natl Acad Sci USA 96:13363-13368

93. Klomp LW, Lin SJ, Yuan DS, Klausner RD, Culotta VC, Gitlin JD (1997) J Biol Chem 272:9221-9226

94. Arnesano F, Banci L, Bertini I, Cantini F, Ciofi-Baffoni S, Huffman DL, O'Halloran TV (2001) J Biol Chem 276:4136541376

95. van Dongen EM, Klomp LW, Merkx M (2004) Biochem Biophys Res Commun 323:789-795

96. Cater MA, Forbes J, La Fontaine S, Cox D, Mercer JF (2004) Biochem J 380:805-813

97. Forbes JR, Hsi G, Cox DW (1999) J Biol Chem 274:1240812413

98. Larin D, Mekios C, Das K, Ross B, Yang AS, Gilliam TC (1999) J Biol Chem 274:28497-28504

99. Strausak D, Howie MK, Firth SD, Schlicksupp A, Pipkorn R, Multhaup G, Mercer JF (2003) J Biol Chem 278:20821-20827

100. Voskoboinik I, Mar J, Strausak D, Camakaris J (2001) J Biol Chem 276:28620-28627

101. Yatsunyk LA, Rosenzweig AC (2007) J Biol Chem 282:86228631
102. Arguello JM, Gonzalez-Guerrero M (2008) Structure 16:833834

103. Tsivkovskii R, MacArthur BC, Lutsenko S (2001) J Biol Chem 276:2234-2242

104. Sanokawa-Akakura R, Dai H, Akakura S, Weinstein D, Fajardo JE, Lang SE, Wadsworth S, Siekierka J, Birge RB (2004) J Biol Chem 279:27845-27848

105. Lim CM, Cater MA, Mercer JF, La Fontaine S (2006) J Biol Chem 281:14006-14014

106. Lim CM, Cater MA, Mercer JF, La Fontaine S (2006) Biochem Biophys Res Commun 348:428-436

107. Stephenson SE, Dubach D, Lim CM, Mercer JF, La Fontaine S (2005) J Biol Chem 280:33270-33279

108. Schroer TA (2004) Annu Rev Cell Dev Biol 20:759-779

109. van de Sluis B, Kole S, van Wolferen M, Holmes NG, Pearson PL, Rothuizen J, van Oost BA, Wijmenga C (2000) Mamm Genome 11:455-460

110. van De Sluis B, Rothuizen J, Pearson PL, van Oost BA, Wijmenga C (2002) Hum Mol Genet 11:165-173

111. van de Sluis BJ, Breen M, Nanji M, van Wolferen M, de Jong P, Binns MM, Pearson PL, Kuipers J, Rothuizen J, Cox DW, Wijmenga C, van Oost BA (1999) Hum Mol Genet 8:501-507

112. Narindrasorasak S, Kulkarni P, Deschamps P, She YM, Sarkar B (2007) Biochemistry 46:3116-3128

113. Tao TY, Liu F, Klomp L, Wijmenga C, Gitlin JD (2003) J Biol Chem 278:41593-41596

114. de Bie P, van de Sluis B, Burstein E, van de Berghe PV, Muller P, Berger R, Gitlin JD, Wijmenga C, Klomp LW (2007) Gastroenterology 133:1316-1326

115. Burstein E, Ganesh L, Dick RD, van De Sluis B, Wilkinson JC, Klomp LW, Wijmenga C, Brewer GJ, Nabel GJ, Duckett CS (2004) EMBO J 23:244-254

116. Maine GN, Mao X, Muller PA, Komarck CM, Klomp LW, Burstein E (2009) Biochem J 417:601-609

117. Spee B, Arends B, van Wees AM, Bode P, Penning LC, Rothuizen J (2007) Anim Genet 38:168-170

118. van den Berghe PVE, Stapelbroek JM, Krieger E, de Bie P, van de Graaf SFJ, de Groot REA, van Beurden E, Spijker E, Houwen RHJ, Berger R, Klomp LWJ (2009) Hepatology (early view)

119. Burstein E, Hoberg JE, Wilkinson AS, Rumble JM, Csomos RA, Komarck CM, Maine GN, Wilkinson JC, Mayo MW, Duckett CS (2005) J Biol Chem 280:22222-22232

120. de Bie P, van de Sluis B, Klomp L, Wijmenga C (2005) J Hered 96:803-811

121. Maine GN, Mao X, Komarck CM, Burstein E (2007) EMBO J 26:436-447

122. van de Sluis B, Muller P, Duran K, Chen A, Groot AJ, Klomp LW, Liu PP, Wijmenga C (2007) Mol Cell Biol 27:4142-4156

123. Liu J, Sitaram A, Burd CG (2007) Traffic 8:1375-1384

124. Piper RC, Luzio JP (2007) Curr Opin Cell Biol 19:459-465

125. Vanderwerf SM, Cooper MJ, Stetsenko IV, Lutsenko S (2001) J Biol Chem 276:36289-36294

126. Vanderwerf SM, Lutsenko S (2002) Biochem Soc Trans 30:739-741

127. Veldhuis NA, Valova VA, Gaeth AP, Palstra N, Hannan KM, Michell BJ, Kelly LE, Jennings I, Kemp BE, Pearson RB, Robinson PJ, Camakaris J (2009) Int J Biochem Cell Biol. doi: 10.1016/j.biocel.2009.06.008 